\title{
La política de la migración en El Salvador desde un contexto global
}

Ann Olesén'

Recibido: 27/09/2014 - Aceptado: 10/11/2014

\section{Resumen}

En el artículo trato de visualizar la política de la migración de El Salvador a través de un recorrido de investigaciones internacionales. La migración ahora no es un fenómeno temporal, sino es una política del Estado como parte de una estrategia de desarrollo para resolver los problemas de la pobreza. Es un proceso político y la creación de una cultura de migración donde las claves para entender ese proceso son las remesas y la feminización de la migración. El regreso de emigrantes implicaría un costo alto a la economía nacional, tanto por la reducción de ingresos como para la reintegración en la sociedad.

\section{Palabras clave}

Migración, política, remesas, cultura, feminización.

\section{Abstract}

In the article I try to visualize the politics of migration in El Salvador going through international research. Migration is no longer a temporary phenomenon but a policy of the state as part of a development strategy to solve the problems of poverty. It is a political process that creates a culture of migration where the keys to understanding this process are remittances and the feminization of migration. The return of emigrants would imply a high cost to the national economy through a reduction of income and their reintegration into society.

\section{Keywords}

Migration, politics, remittances, culture, feminization.
"Los movimientos físicos a través del espacio es lo natural, normal, dada la vida social humana; lo que es anormal, cambiable e históricamente construido es la idea que sociedades humanas necesitan construir fronteras e instituciones políticas que definen y restringen la movilidad espacial en manera particular, regularizadas, en una manera que la inmovilidad sea la norma" (Favell, 2008:271.)

\section{Introducción}

En una investigación que hice sobre la organización de mujeres en movimientos locales de El Salvador (Olesén, 2008), Marta me contó que ella tiene dos hijas en Estados Unidos. Se fueron allá para tratar de mejorar sus vidas y ayudar a su familia. "Ellas no se sienten bien, conscientes de que el país no es el de ellas" — dice Marta-. Y continúa:

\footnotetext{
La autora es profesora e investigadora de la Escuela de Antropología de la Utec, es Doctora en Filosofía con especialidad en la pedagogía antropológica, Maestría en Ciencias Sociales, Licenciatura en Ciencias Sociales, programa de investigador dentro de Ciencias del Comportamiento Humano, Licenciatura en Humanidades con especialidad en Antropología Social, titulaciones obtenidas en la Universidad de Estocolmo, Certificada en prensa sindical de la Escuela de Periodismo, Poppius. Posee un Curso Superior sobre la filosofía de Simone de Beauvoir, de la Universidad de El Salvador. E-mail annolesen@outlook.com y annolesen@hotmail.com
} 


\begin{abstract}
Nosotras arrendamos (la tierra) para trabajar la milpa. Casi la mayoría de las personas alquila para trabajar en los cultivos de maíz, frijoles... Solo para sobrevivir, nada más. Fíjate que en eso es muy difícil. ¿Sabes que cada familia sabe de dónde sobrevive? Por ejemplo, en estos casos, alguien tiene que tomar la decisión y decir que 'yo voy a ver a dónde hay trabajo'.
\end{abstract}

La pobreza es un motivo para que la gente deje sus casas por un futuro poco firme en un país a menudo extraño. "ES la necesidad lo que empuja a los adolescentes a dejar el país, pero no es fácil tomar esta decisión. Pero ¿qué hay que hacer cuando no hay trabajo?", me dijo un político salvadoreño de la derecha. La migración puede ser vista como una respuesta a la sociedad por la falta de educación y trabajo, como por la creciente violencia (Olesén, 2008).

En julio 2010, El Salvador fue anfitrión de una conferencia iberoamericana sobre migración y desarrollo, ofreciendo un espacio para discutir cómo facilitar el proceso de migración, las transferencias de dinero, y cómo esas transferencias tienen un impacto significativo en el desarrollo socioeconómico de los países emisores. La conferencia señaló la importancia de divulgar conocimientos sobre el papel significante que los migrantes tienen en el desarrollo de sus países de origen y cómo visibilizar los costos que los países emisores tienen para la educación y pérdida de capital humano, negando con esos hechos que los migrantes sean una carga para los países recibientes. Los y las participantes indicaron la importancia de fortalecer los lazos con la diáspora por encima del tema de las remesas. Lo que fue discutido es que ellos, como países emisores, deberían tomar un papel mucho más activo para influir en los migrantes para que hagan inversiones en sus países de origen en forma de programas y proyectos que estimularan el intercambio de conocimiento y regresos temporáneos en apoyo de asistencia técnica, promoción de inversiones y el desarrollo de encuentros virtuales. El uso de la tecnología informática en ese trabajo tiene la meta de apoyar a los migrantes, así ellos continúan enviando remesas e invierten en sus países de origen.

Entonces, la migración puede ser vista por los migrantes como una solución para salir de la pobreza y una respuesta a una sociedad que no logra ofrecer trabajo y condiciones dignas para estudiar a todos, pero que lucha para facilitar el proceso a través convenios y compromisos políticos $y$ el fortalecimiento de los lazos con los migrantes en sus países de residencia. Me pregunto si el Estado está mirando la migración como una institución social y política para resolver los problemas de pobreza. En la Antropología una institución social es una práctica, una estructura práctica o formal, que se mantiene y se reproduce de forma independiente de las personas que en un momento dado aparecen en ella (Eriksen, 2000:42). ¿Estamos mirando la institucionalización de la migración como parte del proceso de desarrollo del país, tomando en cuenta la importancia de las remesas para la economía de El Salvador?

El 3 de octubre de 2014, el Ministerio de Hacienda presentó el Proyecto de Presupuesto para el ejercicio fiscal 2015, por 4. 823 millones de dólares, con un incremento del $3 \%$ en relación con el votado para el 2014 (http://www.mh.gob. sv). En comparación, las remesas familiares han alcanzado 3.153.3 millones de dólares recibidos al mes de septiembre 2014, según el Banco Central de Reserva (BCR). Eso muestra la importancia de las remesas en la economía salvadoreña. El presidente del BCR, doctor Óscar Cabrera Melgar, en una reunión con las siguientes comisiones de la Asamblea Legislativa: Hacienda y Especial del Presupuesto; Economía y Financiera presentó un análisis completo sobre los principales indicadores económicos del país. Explicó que se tiene una proyección de crecimiento del 2,2 \%; y en gran medida se debe al crecimiento de las remesas familiares al $8,1 \%$, que dinamizará el consumo privado (http://bcr.gob.sv).

La migración como estrategia de desarrollo del Estado llega a ser muy obvia con la declaración de un funcionario público que decía que los salvadoreños afuera son el mejor producto del país (Santillán, 2005:104). Uno puede concluir, como un representante de Unicef en una reunión de alto nivel en la Universidad de Tecnológica de El Salvador (Utec), el 29 de octubre 2014, que "con un nivel de remesas que corresponde a $18 \%$ del PIB el Estado está usando su gente". Hay líderes de diferentes países que no quieren que sus migrantes regresen en una forma permanente porque eso implicaría una presión enorme a la economía nacional, tanto a causa de una reducción de las remesas como a un aumento en los costos para su reintegración en la sociedad.

\section{La historia de la migración de El Salvador}

Es una historia larga que comenzó con su independencia y el cultivo del café. Las fincas de café siempre necesitaban jornaleros. Entonces comenzó la migración interna. Durante la gran depresión en el siglo XX, al fin de los años 20 y principio de los 30 , cuando cayó el precio del café, la primera ola de emigrantes llegó a Honduras. Según Menjívar (2000), 25000 salvadoreños se fueron a ese país en la década de 1930; y por el final de los 40 eran 100000 salvadoreños los que vivían en Honduras. A mediados de los años 60 el número de salvadoreños en Honduras había aumentado a 350 000. La migración seguía incrementándose en esa 
época por el desarrollo industrial y la diversificación de la agricultura del país, que creaba un desempleo en el área rural. La combinación de represión política, la guerra civil y la situación económica del país desde los años 70 ha cambiado radicalmente la ola mayor de migración que ahora se dirige hacia el Norte y al este cruzando el Atlántico. La gente sigue buscando maneras de emigrar. Nunca ha parado el sueño de una vida mejor, la oportunidad única para mucha gente de seguir adelante.

En el 2005, el Programa de las Naciones Unidas para el Desarrollo (PNUD) presentó el "Informe sobre Desarrollo Humano, El Salvador 2005" (Idhes) titulado "Una mirada al nuevo nosotros. El impacto de las migraciones". Según el informe, el Ministerio de Relaciones Exteriores para el 2002 calculó que la población salvadoreña en los Estados Unidos iba a llegar a 2.5 millones; y eso es equivalente a 40 $\%$ de la población que vive en El Salvador. Según estudios demográficos (Teitelbaum, 2008), solo hay unos pocos países que pueden mostrar una tasa de migración de más de $10 \%$ de su población. Esos países son Haití, Afganistán, Ruanda y Cuba. También México, conocido por su exportación de mano de obra a Estados Unidos, lo que indica que menos de $10 \%$ de su población vive afuera del país.

\section{Los diferentes rostros de la migración}

La migración tiene varios rostros y se expresa de diferentes maneras porque la decisión de marcharse se trata de una interacción entre tres niveles: el macro, que es la estructura política y económica global; el micro, que se compone de la red social personal; y el meso, que consiste en todos los contactos necesarios para que el proceso de migrar se logre, es decir, diferentes organizaciones y coyotes (Keeley, 2009:38).

Todas las migraciones no son semejantes. Hay diferentes clases de migración: las temporales, las definitivas y las transmigraciones. Lo que tienen en común es que se influyen por la estructura económica de diferentes niveles; por las conexiones diplomáticas entre los países emisores y recibientes; y por la relación entre la muestra de migración y estructura familiar. Unas son legales, otras ilegales. Lo que hace al migrante ilegal diferente es que el Estado nacional ha decidido nombrar ese movimiento de esa manera; así, establece su propia soberanía (Favell, 2008:272). En 1990, la Organización de las Naciones Unidas (ONU) aceptó el convenio The International Convention on the Protection of the Rights of All Migrant Workers and Members of Their Families para defender sus derechos humanos, pero pasarían 13 años para que la convención entrara en vigor. Todavía en 2014 solo 47 de 191 países han ratificado la Convención.
Ninguno de los diez países que reciben la mayoría de los migrantes en el mundo se encuentra entre los firmantes del Convenio. Como grupo, esos países reciben la mitad de las personas migrantes del mundo. Pero, cuando el Estado necesita mano de obra o quiere apoyar a un país que ha vivido una catástrofe natural o una guerra, el Estado puede formar parte de un convenio con un país emisor para legalizar una migración temporánea, como pasó entre Estados Unidos y Honduras después el huracán Mitch (Keeley, 2009:37). Esa manera de manejar la migración podría ser vista como una forma de asistencia catastrófica. El gobierno de El Salvador parece encontrarse en una permanente negociación y renegociación con el gobierno de los Estados Unidos sobre la legalización temporánea de los migrantes salvadoreños sin papeles, que son, por su número, un grupo más grande que el de los legales.

Uno debería preguntarse si hay una estrategia consciente detrás del hecho de que cientos de miles de gente viven como ilegales en Estados Unidos. Los ciudadanos salvadoreños en Estados Unidos parecen formar la columna vertebral de la economía nacional de El Salvador. Entonces, ¿qué pasaría, cómo influiría en la economía salvadoreña un colapso económico de Estados Unidos? Sin las remesas ¿el país tendría un colapso total y profundo? Por otro lado, ¿para que serviría la migración, legal e ilegal, a Estados Unidos? ¿ES posible pensar en un país, una nación, como una propiedad privada, como una joya en la bandera estadounidense? Como la India - la joya en la Corona Británica-, durante el imperialismo británico; El Salvador, como un recurso económico para el desarrollo de Estados Unidos... Así, ¿será posible entender la relación entre Estados Unidos y El Salvador? Entonces, ¿los más o menos dos millones de inmigrantes salvadoreños que viven en Estados Unidos son parte de esta política económica?

\section{Las remesas}

Entre 1960 y 2005 la migración internacional se duplicó, según Morrison et al. (2008); y una de las causas de ese aumento en el movimiento migratorio es las remesas: en el presente, alrededor de 200 mil millones de dólares al año. Las remesas tienen importancia económica y política para mantener la estabilidad. Dulce María Moncada García ve la migración de Indonesia a Malasia como un susidio indirecto (2006:152). Eso es un pensamiento muy interesante que puede ser trasladado a la migración de El Salvador a Estados Unidos. La idea es pensar en los y las migrantes como capital humano que contribuye al desarrollo en los países recipientes, mientras el costo para su educación etcétera, fue pagado por el país de origen. Una mirada a la migración desde esa perspectiva, es un subsidio a la economía del país. 
En ese momento sería prudente discutir si las remesas en verdad contribuyen al desarrollo de los países de origen de los migrantes o si es al revés, que el envío de dinero lleve a el desarrollo del subdesarrollo; un pensamiento que fue transmitido en los años de 1960 por André Gunde Frank, conocido como el creador de la teoría de la dependencia. Él fue un economista y sociólogo alemán que vivió y trabajó durante muchos años en Chile. Resultados de investigaciones sobre mujeres filipinas en Italia muestran que ellas migran para que sus familias tengan una mejor vida, pero que la ayuda mandada a las familias la gastan en cosas innecesarias como ropas y joyería:

La obligación sin límites que ellas sienten en apoyar a sus familias extendidas han empujado a las sirvientas domésticas filipinas en un sacrificio sin fin, cuyo resultado obtenido es una dependencia y pereza de los familiares en las Filipinas (Filipino Women's Counsil, 2006:64).

Según un representante en la reunión en la Utec, el 29 de octubre 2014, las personas migrantes son vistas como héroes por dar una calidad de vida mejor a sus familiares en El Salvador; por todas las cosas materiales que estos pueden comprar. Uno puede preguntarse si eso es calidad de vida en una sociedad de consumistas.

Las remesas son dinero privado que generalmente no es invertido de una manera productiva (UNFPA, 2006a:13), entonces, es impreciso si las remesas contribuyen realmente a la reducción de la pobreza o, al contrario, pueden aumentar las brechas sociales en los países en desarrollo, que ya tienen grandes brechas entre la gente que vive de un dólar al día y las personas que viven de un dólar al segundo. Según UNFPA (2006a:12) los emigrantes temporáneos mandan más remesas que los permanentes. La red social del migrante y la intención de regresar también influyen en la cantidad de remesas enviadas. Latinoamérica y el Caribe recibieron más dinero que ninguna otra región del mundo entre los años 1990-2003. De casi mil millones de dólares, los migrantes mandaron, según Oladeinde (2006:112), a sus países de origen las siguientes cantidades en los años:

1990: 5.7

1995: 12.9

2001: 22.9

2002: 26.8

2003: 29.6

Al ser comparado esto con la región que recibió detrás del mejor, Asia del Sur:
1990: 5.6

1995: 10

2001: 13.1

2002: 16.9

2003: 18.2

En el 2004, de cada 100 dólares que entraron en El Salvador, 70 fueron de remesas; y según el Idhes 2005, de cada dólar recibido, ochenta centavos se fueron para el consumo. Entonces, solo una suma marginal va para estudios o a la inversión en un negocio. A veces la pobreza es tan significante que no hay espacio para ahorrar; pero también hay una cultura de consumismo bien fuerte, que influye mucho en el comportamiento de la gente, igual que, como podemos ver en el ejemplo, las Filipinas.

Unagran parte de la investigación sobre migraciones tiene una perspectiva económica, es decir, se trata de costo-beneficio, análisis de diferentes modelos de migración (Pfeiffer et al., 2008; Richter y Taylor, 2008; Pfeiffer y Taylor, 2008; Guzmán et al., 2008). Esos análisis costo-beneficio muestran que los filipinos transfieren más dinero que las filipinas. Como una mayoría de las filipinas trabajan de domésticas en familias es muy probable que ellas no ganen tanto como los filipinos. La sociedad filipina ve a la migración femenina, a la larga, como algo positivo, aunque muchas mujeres trabajan en el campo, y por eso contribuyen con una parte importante a la subsistencia de la familia; sus remesas sustituyen la pérdida de su mano de obra (Pfeiffer y Taylor, 2008:120). En resumen, Guzmán et al. (2008:127, 147-148), después de haber revisado una gran cantidad de literatura, concluyen que las mujeres quieren que sus remesas sean utilizadas para fortalecer el hogar: comida, ropa, utensilios domésticos, muebles; y para educación, salud y amortizar préstamos. Los hombres tienen otro enfoque. Ellos quieren gastar sus remesas en construir casas, la compra de carros y otros artículos de capital. Tener deseos sobre cómo usar las remesas no es lo mismo que tener influencia sobre cómo usarlas. Por la distancia y las dificultades para poder regresar a visitar su lugar de origen para supervisar el uso del dinero enviado, la influencia de los que remesan disminuye considerablemente. Guzmán et al. encontraron que cuando es el hombre el que manda el dinero su mujer lo gasta primero en educación para los niños, mientras que, cuando las remesas son enviadas por la mujer, el hombre de la familia prefiere usarlas para comprar artículos de capital. Eso muestra que la influencia sobre el uso de las remesas está en la persona que se queda y no en la que manda el dinero del extranjero. Si el migrante se queda en el país de origen, su influencia sobre el uso del dinero se vuelve más importante. La persona que queda en la casa consigue un poder sobre las decisiones del hogar que la persona lejana no puede controlar. 
Cuando hablamos de remesas, a menudo son las transferencias económicas a las que nos referimos; pero la migración también implica la transmisión de nuevas ideas, actitudes, conocimientos y habilidades. Brettell y Hollifield nos presentan un pensamiento interesante de teóricos económicos (Massey et al., 1993:438; en Brettell \& Hollifield, 2008:11), acerca de que la gente no solo migra para mejorar la economía de la familia, sino, también, para aumentar su ingreso en relación con otras familias, es decir, como una estrategia para disminuir la pobreza relativa en comparación con otro grupos en la sociedad de referencia. De esa perspectiva, es posible ver como el migrante incrementa el estatus social de su familia en su país de origen. Durante su trabajo de campo en Francia, entre mujeres portuguesas, Brettell (2003:42) encontró que, en la toma de la decisión de migrar, condiciones dignas de trabajo fue un factor más importante para las mujeres que las posibilidades económicas.

\section{¿Quién emigra?}

¿Quién es el migrante? ¿cuáles son los estereotipos sobre los migrantes que existen en una comunidad? Los estereotipos del migrante son imágenes del Sur construidos en el Norte, lo que Reddy (2006:215) llama el surismo: "El surismo puede definirse como una construcción cuidadosa en el Norte y por el Norte de las identidades y culturas de individuos $y$ poblaciones en el Sur; /.../".

Es decir, vivimos en la globalización, pero en una globalización construida por el Norte. No es una globalización verdadera, una construcción de un mundo multicultural.

¿Cuál es la diferencia entre el migrante y la persona que se queda en su tierra? Chiswick (2008:64) escribe que se dice a menudo que las personas que migran son diferentes a las personas que dejan su país de origen, y a la gente que encuentra en el nuevo país. A veces se describe a los migrantes como más agresivos, dispuestos a tomar más riesgos; con una habilidad de planificar y organizar su vida más desarrollada; con un espíritu para hacer negocios y con buena salud. En otros contextos, los migrantes son pintados como refugiados debido a la pobreza y la opresión; unos huyendo de un sentido de estar encerrados en su mundo de nacimiento y crecimiento, mientras otros son atraídos por algo que ellos captan como un paraíso de oro y miel, de muchas posibilidades y de libertad para vivir una vida anónima, sin la presión social que podemos experimentar en nuestros ambientes familiares. Boyd (2006) indica que las personas necesitan alcanzar un cierto estatus social y un nivel económico para tomar la decisión de migrar, es decir, que se requiere un cierto nivel de empoderamiento para dejar su vida con la intención de crear una nueva. Esa declaración puede ser discutida, como pobreza y opresión en sí son fuerzas motrices poderosas.

El contexto influye en los procesos de migración y en la integración en los países recipientes. El contexto consiste en lo que Salazar Parreñas (2001) llama instituciones claves de la migración, que son: el Estado nacional, qué tipo de política migratoria tiene el gobierno; la familia, es decir, la composición del hogar y su economía; el mercado laboral en el país de origen y en el que recibe a los migrantes; y la organización de la sociedad de inmigrantes. El contexto se trata del sentido de pertenencia o exclusión en su país de origen respectivo y en el país destinatario. Para muchos migrantes es el sentimiento de ser excluidos lo que se les hace tomar la decisión de irse en búsqueda de una pertenencia a una sociedad migrante, allá; si no por otra cosa: se hacen importantes por las remesas que puedan mandar a la familia. Brettell (2003:64) escribe: "En migrar, migrantes portugueses están buscando afuera su propio sistema social para una manera de obtener prestigio y movilidad social al dentro ese sistema".

En lugar de quedarse en su pueblo y luchar por mejores condiciones de vida, el migrante abandona su país para cambiar y mejorar su estatus social en su país de origen. En un contexto donde los títulos están ausentes, serán el dinero y lo que el dinero puede comprar lo que marcará la diferencia. Pero en el contexto portugués, que Brettell describe, esta nueva riqueza no lleva un cambio del estatus social fuera del pueblo. Por lo tanto, migrar implica una movilidad social un poco extraña, una que se basa en la distancia geográfica y social entre el hogar y el país anfitrión: el migrante como una persona que trabaja con sus manos en Francia con el fin de no tener que trabajar con sus manos en su país de origen. Cuanto más alto es el estatus social que el migrante logra en su tierra natal, en eso se basa el retorno, no necesariamente un retorno permanente, sino en que los inmigrantes vuelvan a su país de origen para visitar o estar en contacto con la familia y la historia local con la intención de volver un día (Brettell, 2003:65-69).

La migración, por lo tanto, lleva una cierta movilidad social para el individuo; pero ¿también la trae consigo un cambio social en el ámbito local? Vivimos en un constante proceso de cambio social; lo que ayer era casi seguro será diferente mañana. La memoria de las personas que migran, sus imágenes, sus recuerdos de su pueblo de origen están congelados en el tiempo, mientras que el desarrollo en la realidad avanza. La migración representa un movimiento social para el individuo y también un desarrollo para su comunidad, que puede adoptar diversas formas, como un 
aumento en el desarrollo, o como un subdesarrollo social debido a que son las personas que pueden trabajar y las educadas, y no las discapacitadas, las que salen de sus comunidades; y las que se quedan son los ancianos y los jóvenes.

\section{La feminización de la migración}

Mujeres siempre han migrado. Tal vez ellas han sido invisibles en las estadísticas, como en tantos casos; pero 1960 ellas formaron el $45 \%$ de todos los migrantes del mundo; para que en 2005 alcanzaran más del $50 \%$. La tendencia en las muestras migratorias de las mujeres es que esta aumenta, mientras la migración de los hombres ha disminuido algo. Después de 1930, más mujeres que hombres han llegado a Estados Unidos y Canadá; y durante los últimos 30 años más mujeres que hombres han emigrado a Australia. Según UNFPA, la mayoría de las mujeres migran para reunirse con su familia, por desempleo y por razones políticas (UNFPA, 2006a:22-23).

Hernández (2006) demuestra que, a pesar de varias investigaciones durante las últimas tres décadas con perspectiva de género, hay una invisibilización de las mujeres. Su situación específica se encuentra marginada dentro de los estudios de la migración; y eso - dice ella- "representa un hueco en la investigación y en la mayoría de teorías de migración, como se afirma desde la teoría de migración específica de género". Ella habla de la feminización de la migración, apoyándose en varios estudios: en que internacionalmente las mujeres son más del $50 \%$ de la población migrante y entre el 70 y $80 \%$ de los refugiados del mundo (Schötters/Treibel 1997); que en 1990 las mujeres constituyen el $46,3 \%$ de la población extranjera en Europa (Sassen, 1996); y en el mismo año, en los Estados Unidos, la población migrante femenina fue más de la mitad de todo los migrantes (Le Breton, 1999).

De los pobres del mundo, el $70 \%$ son mujeres, pero no solamente es la pobreza lo que las empuja a migrar en la búsqueda de una vida mejor, también es la opresión que ellas enfrentan justo por ser mujeres; una opresión religiosa, política, social y/o económica. Varias de ellas no ven un futuro en el campo donde pautas tradicionales muchas veces oprimen a las mujeres y niñas, por eso ellas migran a las ciudades para buscar trabajo y escapar de la presión de la familia. Adjei (2006:52) escribe: "La migración permite a las mujeres romper con las papeles tradicionales y las muestras de dependencia e imponer una autonomía sobre sus vidas, primero por un incremento en ingresos $y$ los beneficios".
La migración tiene varias caras. La experiencia de migrar puede contribuir al fortalecimiento de la autoestima de las mujeres; ellas se empoderan (UNFPA, 2006 b: 25), mientras que para otras la migración lleva una experiencia de explotación y abuso. Cada vez con mayor claridad resulta ser que, cuando las mujeres carecen de poder y tienen baja autoestima, son más propensas a sufrir violencia (Redpath, 2006:85; Carballo, 2006:96; Menjivar y Salcido, 2002:96). También, Boyd (2006:33) muestra que las jóvenes solteras que emigran podrían perder su estatus en su país de origen: "Un padre opinó que su hija migrante probablemente no encontraría un marido cuando regresara".

Otras razones para que las personas dejen sus países de origen son para estudiar y realizar sueños. La vida urbana tiene una fuerza de atracción poderosa para jóvenes rurales que a través de los medios pueden adivinar lo que esa vida tiene que ofrecer. También, en ciertas sociedades la migración puede ser vista como un rito de pasaje; algo que uno debe hacer para ser adulto; algo parecido a bautizarse o casarse (Cohen, 2004). Buscar una nueva vida no es fácil, como no es fácil romper con papeles tradicionales.

The Global Care Chain (UNFPA, 2006a: 25) es una cadena global; es un sistema internacional de enfermería social y étnicamente estratificada. Se compone de empleadas domésticas y niñeras que cuidan de los hogares y familias de otras personas, mientras que sus propios hijos e hijas son cuidados por los familiares de esas mujeres. De acuerdo con el UNFPA (2006a: 51) trabaja el $60 \%$ de todas las migrantes latinoamericanas en este sector. Gloria MorenoFontes Chammartin (2006:79) utiliza el término movilidad de reemplazo para describir el hecho de que estas mujeres toman el lugar de las mujeres de clase media en el hogar de estas, para que a su vez puedan dedicarse a trabajos mejor pagados con un estatus más alto. Son las mujeres que sustituyen a las otras mujeres que se encuentran en una posición en la que puedan alcanzar un estatus social más alto en la sociedad; son las criadas que contribuyen a este movimiento social ascendente.

La educación es un factor importante para los inmigrantes en el mercado de trabajo. Özden y Neagu (2008) nos indican que migrantes con una formación académica obtienen trabajo con más facilidad que migrantes con una formación escolar baja, que tienen un grado de desempleo más grande. La parte femenina en el mercado laboral, también, depende de la pertenencia religiosa y las tradiciones culturales. Por ejemplo, hay menos mujeres pakistanís con baja educación que con un grado académico que trabajan, pero en la vida laboral las mujeres pakistanís con un postgrado son menos en comparación con todas las mujeres académicas. 
Generalmente las migrantes latinoamericanas tienen un bajo nivel de educación, y, además, lo interesante es que su nivel de educación es más bajo que el nivel promedio en sus países de origen, es decir, son ellas, a las que les falta educación, las más pobres, las que migran. Eso en contraste con migrantes de Asia, África y el Medio Oriente, que por término medio tienen un nivel más alto de educación, aun cuando el nivel educativo en sus países de origen es más bajo (Özden \& Neagu, 2008:162).

Muchas mujeres anhelan su país de origen. Pero investigaciones han mostrado que las mujeres a menudo son más vacilantes a regresar a sus países de origen que los hombres, porque implicaría que ellas tendrían que renunciar a muchas de las ventajas que se han ganado por migrar (Barou, 1996; en Brettell, 2008:128); y en un estudio comparativo sobre el regreso a diferentes países, Gmelch \& Gmelch (1995; en Brettell, 2008:128) encontraron que las mujeres se sintieron menos satisfechas con estar "en casa" y tenían más problemas en adaptarse a su nueva situación que los hombres. De su trabajo del campo en Francia entre migrantes portugueses, Brettell (2003:194) descubrió que las mujeres casadas muchas veces fueron menos dispuestas a regresar a casa que sus maridos. Las mujeres se sentían más integradas en Francia, en parte debido a sus trabajos como sirvientas domésticas y porteras, mientras sus maridos trabajaban en fábricas encerrados con menos contacto con la sociedad. Las mujeres se integran más rápido en la sociedad a través de sus contactos con instituciones locales, como las escuelas, guarderías e instituciones sociales, según un informe de UNFPA (2006a:30). Al revés, hay estudios que muestran que las mujeres tienen una tendencia a readaptarse más fácil que los hombres porque han mantenido el contacto con su país y con su red social allá. Ellas encuentran muchas veces un camino para reintegrarse como pequeñas empresarias a través del capital que ellas han logrado ahorrar, según Adjei (2006:54).

¿Qué es el hogar? Eliade (1968:32) escribe: "Establecerse en un país es lo mismo como crearse un mundo". Pero no tiene por qué pertenecer. El hogar puede ser un lugar físico o una situación, los lugares no existen en sí mismos, sino que tiene significado por el sentido que les damos, por lo tanto, no deben ser visibles de la manera que existen en nuestra conciencia (Olesen, 1999:6). La casa para el emigrante puede ser, con las palabras de Tuan (1977:138), una pausa en el movimiento; un lugar para venir a ganar fuerza; una localización en la memoria y una ubicación física. Los migrantes crean un mundo en el país receptor, pero no necesariamente una casa. El hogar es de donde usted viene, está lleno de recuerdos y de relaciones, la confianza y una identidad social como Alguien con estatus social, en contraste con el Nadie sin estatus, que es como muchos migrantes se sienten en el país anfitrión. Una señal tangible de donde el hogar está se vuelve "la casa" que tantos inmigrantes construyen en su pueblo natal no solo como un símbolo de su éxito en el extranjero (Brettell 2003:64), pero también para manifestar su afiliación. Esta dimensión del transnacionalismo ha sido creada y desarrollada desde la perspectiva del migrante, pero hay otra dimensión que Glick-Schiller (1999:95; en Brettell, 2003: xvii) describe que ha evolucionado a partir de los dirigentes políticos de los países emisores, lo cual contempla y fortalece la imagen de sus Estados como transnacionales. Los líderes de muchos países no quieren que sus emigrantes regresen permanentemente porque sería una enorme presión sobre la economía, tanto por la disminución de las remesas como por el aumento de los costos para integrar a los regresados a la sociedad. Entonces, la casa de verano es una solución excelente para las visitas temporales al pueblo de origen.

\section{La política}

En su artículo "The Politics of International Migration", Hollifield (2008) se pregunta por qué uno debe molestarse con estudiar ese fenómeno cuando en la practica la gran mayoría de la humanidad vive y muere, si no en su pueblo natal en la misma área geográfica en donde nació. La mejor repuesta que él puede dar es que la migración internacional crea un sentido de crisis porque ella sigue aumentando, y ahora ha llegado más allá de todos los controles estatales y de las sociedades. Ello asusta. Ello crea un miedo para lo desconocido, para lo que es diferente. Los análisis económicos y demográficos se enfocan en recursos escasos que más gente compartirá. Estas investigaciones postulan que todas las sociedades tienen recursos limitados y que estos primero deben ser reservados para la población nacional.

Según una investigación hecha por The Wall Street Journal y NBC News en Estados Unidos, más de la mitad de los participantes, $52 \%$, tenían la opinión que la inmigración ha hecho más daño que utilidad para el país (Keeley, 2009:14); al mismo tiempo, como $28,4 \%$ de la gente que trabaja en hoteles, restaurantes y con turismo en Estados Unidos son inmigrantes legales (Moreno-Fontes Chammartin, 2006:78). Esos trabajos muchas veces son mal pagados, pesados, sucios, con horarios irregulares. Generalmente no son trabajos atractivos. Mucha agua ha corrido en el río Hudson después de que fue hecha la inscripción en la Estatua de Libertad, en su desembocadura: "Denme sus cansados, sus pobres, su multitud acurrucada..." (Keeley, 2009:20). 
Un factor importante en cómo muestras de migración se forman es el papel del Estado en la creación de una política de migración. En muchos de esos países emisores los gobiernos promueven la exportación de mano de obra por un fuerte aumento en la población que el país no puede manejar, entre otras razones por la mala o no existente educación sexual, que muchas veces tiene raíces religiosas. Esa exportación de mano de obra implica un aumento en los ingresos del Estado por las remesas; además, implica más posibilidades de exportación de mercancía para el país emisor porque en el país recibidor se crea un mercado para productos de los países de origen de los migrantes. Inmigrantes viven con un anhelo de aromas y sabores de sus países de origen. A Estados Unidos, El Salvador exporta queso y frijoles, horchata y cebada. Además, si el aumento en el crecimiento de la población lleva a un desempleo grande, los riesgos de alborotos y una inestabilidad política aumentan. La política de migración puede expresarse en una manera pronunciada o sobrentendida, como una política formal, alternativa como una práctica informal. Teitelbaum (2008) menciona varios países en diferentes continentes que se caracteriza por ese factor político: Filipinas, Bangladesh, India, Vietnam, Turquía, Pakistán, Indonesia, Corea del Sur, Jordania, Yemen, Egipto, México, República Dominicana, El Salvador, Guatemala, Nicaragua, Barbados, Marruecos y Túnez. También, él indica a otros factores para entender los grandes movimientos de gente como consecuencia de diferentes tipos de opresión, como guerras, violencia intrafamiliar, persecución política y étnica, abuso de los derechos humanos, estagnación económica y hambruna. Como ejemplos de países que viven esos tipos de opresión, él menciona: Afganistán, Myanmar, Turquía, Corea del Norte, Irak, Kuwait, Nicaragua, El Salvador, Cuba, Haití, Ruanda, Burundi, Zaire, Mozambique, Sudán, Somalia, Kosovo, Bosnia, Croacia y lo demás países europeos antes, durante y después la segunda guerra mundial.

Según el representante de Unicef, en la reunión en la Utec antes mencionada, hay una falta del Estado salvadoreño de protección de niños, niñas y jóvenes. En las áreas urbanas, 47 \% finaliza el bachillerato; en la rural, solo $27 \%$. En 2013, de la población entre 4 y 17 años 284325 no asistían a la escuela; y el abuso de ese grupo ha aumentado $160 \%$.

Durante toda la historia de la humanidad, los seres humanos han caminado dirigidos por la necesidad y la curiosidad, que se fecha hacia atrás entre 50 y 60000 años, caminatas que comenzaron en el oeste de África, llevándolos hacia Oriente Medio, seguidamente hacia la península Árabe, después dirigiéndose hacia India y al Sureste de Asia para cruzar el mar hacia Australia. Más tarde en la historia los éxodos se movían hacia el sur y norte de Europa, al centro de Asia y por el estrecho de Bering bajando al continente americano (Keeley, 2009:21). La literatura de las migraciones se trata, a lo largo, sobre migraciones de países pobres a países ricos. En la realidad esa migración solo constituye una tercera parte de todas las migraciones, mientras otra tercera parte son migraciones del norte al norte; $y$ el resto de las personas migran del sur al sur, según Keeley (2009:31).

En 2006, los Estados Unidos recibió 1266300 inmigrantes legales, la cantidad más alta del mundo, mientras el Reino Unido, en segundo lugar, recibió 204300 migrantes legales, seguidos por Canadá, 251 600; Italia, 204 300; e Irlanda, que recibió solo 88900 . Interesante es que, en relación con su población, Irlanda recibió la cantidad más alta del mundo: 21.1 por 1000 habitantes, mientras los Estados Unidos solo recibió 4.2 por 1000 . Algunos países recibieron, en comparación, pocos migrantes legales: Austria 46400 , Noruega 28000 y Dinamarca 21 700; pero en relación con su población, ellos recibieron más inmigrantes legales que Ios Estados Unidos: Noruega 6.0, Austria 5.6 y Dinamarca 4.0, este último casi como Estados Unidos. Asimismo, el Reino Unido y Canadá recibieron más migrantes per cápita que Estados Unidos: 5.7 respecto a 7.8.

Pero la gran mayoría de la gente se queda en sus casas. Para el 2010 había 214 millones de migrantes en el mundo, de una población de casi 7 mil millones (Population Reference Bureau), es decir, que, en la realidad, solo es el $3 \%$ de la población mundial la que vive fuera de sus países de origen. La mayoría de esta población migrante esta en la búsqueda de mejoras económicas y sociales, y pocos de entre ella son refugiados. Según los cálculos de UNFPA (2006 a), en 2005 había 12.7 millones de refugiados en el mundo, de ellos $90 \%$ vivían en sus países vecinos; los refugiados representaban $18 \%$ de la migración internacional en África, $15 \%$ en Asia y $3 \%$ en Europa.

Hay una asimetría en ese proceso global porque mercancías, capital, información e ideas flotan libremente a través las fronteras nacionales, pero el capital humano no, nos encontramos con restricciones, fronteras cerradas, la exigencia de visa. ¿Por qué? Puede ser una manera, para el país receptor, de proteger su legislación laboral y sistema de pensiones contra inmigrantes ilegales que son mal pagados y muchas veces son contratados y trabajan fuera de dicha legislación laboral. Los inmigrantes sin documentos ascienden entre 30 y 40 millones a escala mundial (UNFPA, 2006a:9-10). Pero a pesar de que la brecha entre la gente rica y la población pobre sigue aumentando en el mundo, la mayor parte de las personas se quedan en casa. No migran. 
La política de la migración crea una cultura. En Portugal, según Brettell (2003:9), la emigrante es uno de los símbolos claves para la identidad nacional. Símbolos pueden ser vistos como expresiones culturales de valores importantes en la sociedad. Pero no se trata de cualquier símbolo, sino de encontrar lo que Turner (1967) llama core symbols y Ortner (1973) key symbols, símbolos que puedan ser identificados como núcleos en la organización de un sistema de importancia cultural para la gente. Esos símbolos juntos pueden ser interpretados y entendidos como una cultura. Lo que estamos tratando de interpretar es el migrante particular como sentido simbólico, como un arquetipo de la imagen de lo que pueda ser una cultura de migración. Brettell (2003:62) expresa que el migrante, visto un arquetipo, es fundamental para la imagen de Portugal como una sociedad de emigración. Las personas migrantes se vuelven símbolos para una movilidad social creada de una ilusión del país receptor como un El Dorado, un país de posibilidades donde uno puede crearse una fortuna rápido y fácilmente. Esa ilusión es engañosa porque esconde la vida dura que el migrante encuentra en la búsqueda de mejorar su estatus social. Lo que el emigrante representa con eso para las personas que se quedan y que pueden ser los próximos es una ilusión, es un comportamiento engañoso que da una imagen falsa de la vida como migrante (Brettell 2003:63). También, la transnacionalización de la vida familiar puede mostrarse como una imagen falsa de la realidad, según Paiewonsky (2006:71), que nos enseña que, según una mayoría de la gente que ella ha entrevistado en la República Dominicana, las mujeres que migran están destruyendo la familia tradicional; y la cultura de migración influye en los jóvenes en seguir en su sendero.

Esa cultura de migración crea países multiculturales que en esta era de globalización pueden ser vistos como naciones globales. "La migración internacional es una de las manifestaciones más directas, evidentes y expresivas de la actual fase del proceso de globalización", escribe Domínguez Ávila (2006:197), cada país en sí es un reflejo del mundo global, multicultural. Las mujeres migrantes son peregrinas, viajeras, igual que los hombres; y la migración es como un pasaje ritual nacional (Brettell 2003:18). El rito de migración, entonces, puede ser visto como la despedida de su pueblo, el tiempo afuera y el retorno al país de origen. El migrante simboliza la identidad nacional de su país y al mismo tiempo se siente como marginalizado en el país receptor. Una mujer griega en Suecia en una ocasión contó que la única vez que ella no estaba anhelando es en el vuelo entre Estocolmo y Atenas. Cuando está en Suecia, añora Grecia; y cuando está visitando su país de origen, le hace falta su vida en Suecia (Olesén, 1989). La identidad migrante es complicada: en Suecia ella es vista como una extranjera de visita o como una inmigrante; al mismo tiempo, visitando su país de origen, ella está descubriendo que es vista como sueca. ¿Cómo podemos entender esa experiencia compleja en que el migrante define su propia sentido de pertenencia? En el mundo transnacional y global, escribe Brettell (2008:123), la persona migrante se encuentra involucrada, consciente o inconscientemente, en la construcción nacional en más de un país, algo que implica que identidades nacionales no solo se vuelven más borrosas sino, también, negociadas o construidas.

\section{Conclusiones}

Ahora, en el mundo global, la migración es una institución, una estructura práctica para resolver problemas políticas. Se ha vuelto una institución sociopolítica para invisibilizar los graves problemas de pobreza que tiene un país. Pero se ha mostrado que no es un camino sostenible al desarrollo ni para vencer la pobreza. Los países remitentes siguen siendo de un nivel bajo del índex del desarrollo humano. Es decir, la población pobre sigue siendo pobre. Lo que el país pierde es capital humano; la migración significa un drenaje de conocimiento y creatividad que es importante para un desarrollo a largo plazo y sostenible.

La migración representa una dinamización de la economía a través del consumo privado que las remesas hacen posible. La política de migración es sumamente importante para la economía salvadoreña, pues corresponde a alrededor de $18 \%$ del PIB; pero las remesas no llevan a una producción sostenible para la exportación que produciría los ingresos necesarios para desarrollar el país. Ahora, una gran parte de las remesas van al consumo privado, a las grandes cadenas de comida rápida, es decir, de regreso a Estados Unidos. Podemos decir que eso es una dinamización porque crea trabajos en la industria de comida, pero realmente no es un argumento sólido dado los bajos salarios.

Sin embargo, políticamente sería un suicidio renunciar a las remesas, a pesar de que el precio que se paga para no perderlas es muy alto. El tráfico de niños, niñas y adolescentes por el crimen organizado, cuyo objetivo no es la violencia sino el lucro, es decir, el uso de las personas jóvenes para su negocio de drogas y prostitución, es un problema que va creciendo por el aumento de niños y jóvenes que viajan solos tratando de cruzar las fronteras. También, considerando la cantidad de personas que han pasado las casas de migrantes en la frontera sur Guatemala-México, según Mauro Verzeletti, de la Red de Casas del Migrante Scalabrini, unos 40000 personas salvadoreñas tratando de cruzar la frontera, perdiendo todo en el camino, hasta lo peor: sus piernas o sus vidas. El migrante está pagando 
un precio muy alto para lograr entrar y vivir ilegalmente en Estados Unidos, para aumentar el consumismo salvadoreño.

La migración representa, también, un movimiento social para la gente que migra y un desarrollo local para su comunidad, creando una cultura que afecta la identidad nacional. Los migrantes construyen casas y hacen pequeñas inversiones en sus pueblos natales, pensando en el regreso; pero la historia ha demostrado que la migración casi nunca regresan. Con el tiempo, la migración se vuelve permanente en la construcción de un nuevo hogar, y muchas veces de una nueva familia. La migración deja un país con pueblos de ancianos, niños y jóvenes. La feminización de la migración ha cambiado de una manera radical la cara de la familia.

Falta mucha estadística sobre migrantes en EE.UU. Tal vez es para esconder la realidad detrás las remesas: las bajas condiciones en que viven los y las migrantes. ¿Es condiciones deplorables el precio que se debe pagar por las remesas? ¿Hace falta una falta política para conocer la realidad de los migrantes en Estados Unidos?

El muro de Berlín cayó en 1989. Ahora tenemos nuevos muros construidos por Estados Unidos e Israel. Además, tenemos los muros invisibles que son muros políticos para proteger un estilo de vida. El desarrollo tiene un precio que implica solidaridad y una voluntad por parte de toda su población de crear una sociedad democrática y de igualdad y equidad para toda su gente.

\section{Referencias}

Adjei, E. (2006). "Impact of Female Migration on Countries of Origin. The Case of Ghana", in UNFPA, (ed.) Bridging the gap. New York: United Nations Population Fund.

Barou, J. (1996). "Portugais d'Auvergne: D'une identité villageoise a l'autre. Revued'Auvergne 3: 147-49.

Boyd, M. (2006). "Push factors resulting in the decision for women to migrate", in UNFPA, (ed.) Bridging the gap. New York: United Nations Population Fund.

Brettell, C. (2003). Anthropology and Migration: Essays on Transnationalism, Ethnicity, and Identity. altnut Creek, CA: Altamira Press.

Brettell, C. (2008). "Theorizing Migration in Anthropology. The Social Construction of Networks, Identities, Communities, and Globalscapes", in Brettell, C. and J.F. Hollifield, (eds.) Migration Theory. Talking across Disciplines. New York and London: Routledge Taylor \& Francis Group.

Brettell, C. and Hollifield, J.F. (2008). "Migration Theory. Talking across Disciplines", in Brettell, C. and J.F. Hollifield, (eds.) Migration Theory. Talking across Disciplines. New York and London: Routledge Taylor \& Francis Group.

Carballo, M. (2006). “Female Migrants, Reproductive Health, HIV/ AIDS and the Rights of Women", in UNFPA, (ed.) Bridging the gap. New York: United Nations Population Fund.

Chiswick, B.R. (2008). "Are Immigrants Favorably SelfSelected? An Economic Analysis", in Brettell, C. and J.F. Hollifield, (eds.) Migration Theory. Talking across Disciplines. New York and London: Routledge Taylor \& Francis Group.

Cohen, J. H. (2004). The Culture of Migration in Southern Mexico. Austin: University of Texas press.

Domínguez Ávila, C.F. (2006). Migración, globalización y relaciones internacionales: en busca de nuevas interpretaciones fundamentadas en evidencias latinoamericanas recientes. En García Gossio, M.L. (ed.) Los Nuevos escenarios de la migración: causas, condiciones, consecuencias. México, Cuba: Fundación Heinrich Böll.

Eliad, M. (1968). Heligt och profant. Verbum.

Eriksen, T. H.(2000). Små platser - stora frågor. En introduction till socialantroplogi. Nora: Nya Doxa. [Small places, Large issues, Pluto Press 1995].

Favell, A. (2008). "Rebooting Migration Theory. Interdiciplinarity, Globality, and Postdisciplinarity in Migration Studies", in Brettell, C. and J.F. Hollifield, (eds.) Migration Theory. Talking across Disciplines. New York and London: Routledge Taylor \& Francis Group.

Filipino Women's Counsil (FWC), Rome, Italy. (2006). "Women from the Diaspora: The example of Filipino Women in Italy", in UNFPA, (ed.) Bridging the gap. New York: United Nations Population Fund.

Glick-Schiller, N. (1999). "Transmigrants and Nation-States; Something Old and Something New in the U.S. Immigrant Experience", in Hirschman, C., P. Kasinitz \& J. DeWind (eds.) Handbook of International Migration: The American Experience. New York: Russell Sage.

Gmelch, G. \& S. Bohn Gmelch. (1995). "Gender and Migration: The readjustment of Women Migrants in Barbados, Ireland, and Newfoundland," Human Organization 54: 470-73.

Guzmán, J.C., Morrison, A.R. \& Sjöblom, M. (2008). “The impact of remittances and gender on household expenditure patterns: evidence from Ghana", in Morrison, A.R., Schiff, M. \& Sjöblom, M. (2008). The International Migration of Women. Washington, DC. A co-publication of the World Bank and Palgrave Macmillan.

Hernández, B. (2006). "Nuevas rutas, nuevas actoras: mujeres migrantes latinoamericanas en Alemania", en Los nuevos escenarios de la migración: causas, condiciones, consecuencias. (coord.) M. I. García Gossio. (2006). México: Fundación Heinrich Böll. 
Hollifield, J.F. (2008). "The Politics of International Migration", in Brettell, C. and J.F.

Hollifield, (eds.) Migration Theory. Talking across Disciplines. New York and London: Routledge Taylor \& Francis Group.

IDHES. (2005). El "Informe sobre Desarrollo Humano: Una mirada al nuevo rostro nosotros. El impacto de las migraciones. El Salvador": Programa de las Naciones Unidas para el Desarrollo (PNUD).

Keeley, B. (2009). International Migration: the human face of globalisation. Organisation for Economic Co-operation and Development - OECD.

Le Breton, B.M. (1999). Illegalisierung und Kriminalisierung der Migrantinnen. "Frauen Handel" im Kontext restriktiver Einwanderungspolitik. En Widerspruch $\mathrm{Nr}$ : 37/99, Zurich, pp. 83-93.

Massey, D.S., J. Arango, G. Hugo, A. Kovaouci, A. Pellegrino \& J. E. Taylor. (1993). "Theories of International Migration: A Review and Appraisal", Population and Development Review 19:431-66.

Menjívar, C. (2000). Fragmented Ties. Salvadoran Immigrants Networks in America. Berkley: University of California Press.

Menjivar, C. \& Salcido, O. (2002). "Immigrant women and domestic violence", in Gender \& Society. Thousand Oaks: Vol.16, Iss. 6:898.

Moncada García, D.M. (2006). Migración laboral de Indonesia a Malasia: estudio de caso. En García Gossio, M.L. (ed.) Los Nuevos escenarios de la migracióncausas, condiciones, consecuencias. México, Cuba: Fundación Heinrich Böll.

Moreno-Fontes Chammartin, G. (2006). “Female Migrant Workers in an era of Globalization", in UNFPA, (ed.) Bridging the gap. New York: United Nations Population Fund.

Morrison, A.R., Schiff, M. \& Sjöblom, M. (2008). The International Migration of Women. Washington, DC.: A co-publication of the World Bank and Palgrave Macmillan.

Oladeinde, F.O. (2006). "Challenges and opportunities faced by returned female migrants", in UNFPA, (ed.) Bridging the gap. New York: United Nations Population Fund.

Olesén, A. (1989). Grekiska tonårsflickor i Hagalund: deras syn på skolan, fritiden, framtiden. Stockholms Universitet, 1989.

Olesén, A. (1999). Tredje ålderns hus - en spansk boendemiljös betydelse för kvinnors livsprojekt. Stockholm: Stockholms universitet.

Olesén, A. (2008). "Un cambio sumamente radical. Empoderamiento por participación femenina - un movimiento social en la vida rural de El Salvador". No publicado.
Ortner, S. (1973). "On Key Symbols" American Anthropologist 75:1338-46.

Paiewonsky, D. (2006). "Gender, Remittances and Development in the Dominican Republic", in UNFPA, (ed.) Bridging the gap. New York: United Nations Population Fund.

Pfeiffer, L., Richter, S., Fletcher, P. \& Taylor, J.E. (2008). “Gender in economic research on international migration and its impacts: A critcal review", in Morrison, A.R., Schiff, M. \& Sjöblom, M. (2008). The International Migration of Women. Washington, DC.: A co-publication of the World Bank and Palgrave Macmillan.

Pfeiffer, L. \& Taylor, J.E. (2008). "Gender and the impacts of international migration: evidence from rural Mexico", in Morrison, A.R., Schiff, M. \& Sjöblom, M. (2008). The International Migration of Women. Washington, DC.: A co-publication of the World Bank and Palgrave Macmillan.

Reddy, P. (2006). "El surismo y la gobernanza global: una contradicción desafiante". En García Gossio, M.L. (ed.) Los Nuevos escenarios de la migración: causas, condiciones, consecuencias. México, Cuba: Fundación Heinrich Böll.

Redpath, J. (2006). "Human Rights of Migrant Women and International Protection Mechanisms", in UNFPA, (ed.) Bridging the gap. New York: United Nations Population Fund.

Richter, S. \& Taylor, J.E. (2008). “Gender and the determinants of international migration from rural Mexico over time", in Morrison, A.R., Schiff, M. \& Sjöblom, M. (2008). The International Migration of Women. Washington, DC.: A co-publication of the World Bank and Palgrave Macmillan.

Salazar Parreñas, R. (2001). Servants of Globalization: women, migration and domestic work. Stanford, California: Stanford University Press.

Santillán, D. (2005). Renegociar las identidades nacionales: Los vínculos transnacionales, los discursos de las diásporas y las comunidades pan étnicas. En La Transnacionalización de la sociedad centroamericana: visiones a partir de la migración. San Salvador: Flacso Programa El Salvador, 2005.

Sassen, S. (1996). Metropol en des Weltmarkts. Die neue Rolle der Global Cities. Frankfurt/New York: Campus.

Schötters, M. \& Treibel, A. (1997). Frauen-Flucht-Migration. Wanderugsmotive von Frauen und Aufnahmesituation in Deutschland. In: Ludger Pries (ed.) Transnationale Migration, Soziale Welt Sonderband 12, pp.85-117.

Teitelbaum, M. S. (2008). "Demographic Analyses of International Migration", in Brettell, C. and J.F. Hollifield, (eds.) Migration Theory. Talking across Disciplines. New York and London: Routledge Taylor \& Francis Group. 
Tuan, Y.F. (1977). Space and Place. The Perspective of Experience. Minneapolis. University of Minnesota Press.

Turner, V. (1967). The Forest of Symbols: Aspects of Ndembu Ritual. Ithaca: Cornell University Press.

UNFPA. (2006a). State of the World Population. A Passage to Hope. Women and International Migration. New York: United Nations Population Fund.

UNFPA. (2006b). Bridging the gap. New York: United Nations Population Fund.

Universidad Tecnológica de El Salvador (2014). El “Primer diálogo de alto nivel sobre migración". Reunión el 29 de octubre en el Auditórium De La Paz

Özden Ç, Neagu, I.C. (2008). “Immigrantwomen's participation and performance in the U.S labor market", in Morrison, A.R., Schiff, M. \& Sjöblom, M. (2008). The International Migration of Women. Washington, DC.: A co-publication of the World Bank and Palgrave Macmillan.

http://bcr.gob.sv/esp/index.php?option=com search\&Itemid=109 consulta 26 de oct.2014.

http://www.mh.gob.sv/portal/page/portal/PMH/Resultado_ de_la_Busqueda Consulta 26 de octubre 2014. 